\title{
Is Facet Analysis Based on Rationalism? A Discussion of Satija (1992), Tennis (2008), Herre (2013), Mazzocchi (2013b), and Dousa \& Ibekwe-SanJuan (2014)
}

\author{
Birger Hjørland \\ University of Copenhagen, Royal School of Library and Information Science, \\ 6 Birketinget, Copenhagen S DK-2300, Denmark, <pnl617@iva.ku.dk>
}

\begin{abstract}
Birger Hjørland holds an M.A. in psychology and Ph.D. in library and information science. He is professor in knowledge organization at the Royal School of Library and Information Science in Copenhagen since 2001 and at the University College in Borås 2000-2001. He was research librarian and coordinator of computer based information services at the Royal Library in Copenhagen 1978-1990, and taught information science at the Department of Mathematical and Applied Linguistics at the University of Copenhagen 1983-1986. He is chair of ISKO's Scientific Advisory Council and a member of the editorial boards of Knowledge Organization, Journal of the Association for Information Science and Technology and Journal of Documentation.
\end{abstract}

Hjørland, Birger. Is Facet Analysis Based on Rationalism? A Discussion of Satija (1992), Tennis (2008), Herre (2013), Mazzocchi (2013b), and Dousa \& Ibekwe-SanJuan (2014). Knowledge Organization. 41(5), 369376. 35 references.

\begin{abstract}
In several writings I have claimed that the basis of knowledge organisation (KO) must be found in subject knowledge, and that researchers and practitioners in KO must achieve knowledge about the domains that they are organising. Domain knowledge is not neutral, but rather is based on competing epistemologies and worldviews, and the classifier is therefore participating in struggles related to worldviews. Different traditions, approaches and paradigms in knowledge organisation research (and practice) can best be understood as more or less associated with one of four epistemologies: empiricism, rationalism, historicism/hermeneutics, or pragmatism/critical theory (of which only the last position fully acknowledges the non-neutrality of knowledge organisation). Ranganathan - and the whole facetanalytic school — has formerly been exemplified as a rather clear example of rationalism. Some have objected to this claim, and Satija (1992), Tennis (2003), Mazzocchi (2013b), Herre (2013), and Dousa and Ibekwe-SanJuan (2014) have each provided important arguments that need to be considered. This paper therefore takes these authors' studies as the point of departure and examines the arguments that have been raised in relation to my position.
\end{abstract}

Received: 29 May 2014; Revised: 15 July 2014; Accepted: 22 July 2014

Keywords: empiricism, rationalism, knowledge, classification, Ranganathan, eclecticism

\subsection{Introduction}

My working hypothesis has been-for a long time-that any kind of knowledge (whether scientific or not) is based on ontological and epistemological presumptions. By implication, research and practices (as well as specific systems) in the field of classification research and knowledge organisation (KO) must also be based on epistemological assumptions (either explicit or implicit).

There are a great many epistemological positions in contemporary discourses: accordingly, the field is crowded, fragmented and somewhat unclear. Hjørland and Nicolaisen (2010) list 43 positions, but it makes no sense to ask how many exist, because many are deeply interconnected. It is also less fruitful to consider each position individually, because some have identical methodological implications for the construction and evaluation of classification systems. An example: from a feminist epistemological point of view, it may be asked whether a given classification reflects a male-dominant point of view and is therefore suppressing feminist views. This way of considering classifications is related to the consid- 
eration of how class interests are reflected, how ethnic interests are reflected and how colonial interests are reflected. Instead of having multiple specific epistemologies for each of these questions, we may say that they all represent a kind of critical-theoretical view on $\mathrm{KO}$, which is again connected with a pragmatic view of knowledge (i.e., knowledge serves practical aims) and therefore knowledge has to be evaluated in relation to which (and whose) practical aims it supports, and to whether other aims and values are relatively suppressed. Therefore, one family of epistemologies may be termed the pragmatic view of knowledge (not to be confused with practicalism, which is a kind of anti-theoretical view). If pragmatism represents one family of epistemologies, which other major families of epistemology exist?

Since the Enlightenment, the classical epistemological antagonists have been defined as rationalism and empiricism. Each of these positions has its famous philosophers, such as the rationalists René Descartes (15961650), Baruch Spinoza (1632-1677) and Gottfried Leibniz (1646-1716), and the empiricists Francis Bacon (1561-1626), John Locke (1632-1704), George Berkeley (1685-1753) and David Hume (1711-1776). It may seem strange that it is necessary or relevant to consider such archaic philosophy alongside modern (information) science. Is it not the general consensus today that all science must be empirical? And has empirical methodology not made great advances in recent times, as is reflected, for example, in methodology textbooks?

Yes, science is empirical, but empirical studies are always made on the basis of sets of assumptions, and assumptions related to rationalism, empiricism and pragmatism are still very much active in contemporary (information) science. Rationalism (Descartes' version), for example, explicitly informed the linguist Noam Chomsky and is an important basis for modern cognitive science. I have claimed previously that the whole facet-analytic tradition must be interpreted as basically rationalist (Hjørland 1997, 2013a). Classical empiricism is also very visible in modern (information) science, for example, in studies collecting information on user behavior, in which users are selected in ways that are neutral in respect to the hypotheses of the researcher. Induction is very much related to empiricism, for example, induction from a sample to the whole population (by the same token, deduction is much related to rationalism, and abduction is related to pragmatism). Logical positivism, which dominated in the first part of the twentieth century, was brought to an end by-among othersThomas Kuhn's (1962) book The structure of scientific revolutions, which may be understood as a historicist and pragmatic turn in the philosophy of science. The main problem for logical positivism has been described in this way (Smith 1986, 64):
Logical positivism arose as the joint product of two intellectual traditions that conflicted deeply with one another [rationalism and empiricism]: In attempting to unite these traditions, its adherents created an extremely influential approach to philosophy but one that embodied serious intellectual tensions from its dual ancestry.

It is the opinion of some researchers (myself included) that rationalism and empiricism are based on common assumptions, which represents a philosophical trap. This trap concerns three common assumptions in particular, listed as follows. Both rationalism and empiricism are based on:

- Individualism/atomism (rather than on holistic/collectivistic/social epistemologies)

- Ahistorical thinking (rather than on historicism/evolutionary epistemology)

- Claimed neutrality (rather than on engagement/political interests/partisanship/values/pragmatic enterprises)

Bruce Aune ([1970] 1995) has written an introduction to three major epistemologies: rationalism, empiricism and pragmatism. Often historicism-rather than pragmatism-is considered the third major theory. Although historicism and pragmatism are closely related (and therefore sometimes difficult to distinguish from each other), I have-in a number of writings - considered these four schools of theory as fundamental to understanding knowledge organisation:

"Rationalist theories of KO" suggest that subjects are constructed logically from a fundamental set of categories. The basic method of subject analysis is then "analytic-synthetic," to isolate a set of basic categories (=analysis) and then to construct the subject of any given document by combining those categories according to certain rules (=synthesis). Also, the applications of other rules, such as logical division, are by principle part of the rationalist view.

"Empiricist theories of KO" are based on the idea that similar (informational) objects share a large number of properties. Objects may be classified according to those properties, but this should be based on neutral criteria, not on the selection of properties from theoretical points of view, as this introduces a kind of subjective criteria, which is not approved by empiricism. Numerical statistical procedures are based on empiricist philosophy. Also, the search for consensus among indexers is an approach that may be interpreted as based on empiri- 
cism: the correct indexing is the one that indexers agree on, and empirical studies of inter-indexer agreement are believed to reveal correct indexing (which is a problematic assumption because, as argued by Cooper (1969), indexing — as done by the majority of indexers - may be consistently bad).

"Historicist and hermeneutical theories of KO" suggest that the subject of a given document is relative to a given discourse or domain and, by implication, the classification should reflect the need of a particular discourse or domain. According to hermeneutics, a document is always written and interpreted from a particular horizon. The same is the case with systems of knowledge organisation, and with all users searching such systems. Any question put to such a system is put from a particular horizon. All those horizons may be more or less in consensus or in conflict. To index a document is to try to contribute to the retrieval of "relevant" documents by knowing about those different horizons.

"Pragmatic and critical theories of KO" are in agreement with the historicist point of view that subjects are relative to specific discourses, but emphasise that subject analysis should support given goals and values and should consider the consequences of indexing. These theories emphasise that classification and indexing cannot be neutral and that it is a misleading ideal to try to classify subjects in a neutral way. Classification is an act (and computer-based indexing is acting according to the programmer's intentions). Acts serve human goals. Libraries and information services also serve human goals, and this is why their classification should be done in a way that best supports these goals. The core of indexing is, as stated by Rowley and Farrow (2000), to evaluate a paper's contribution to knowledge and index it accordingly; or, with the words of Hjørland (1997), to index its informative potentials. What is known as "request-oriented indexing" (not to be confused with user-based indexing) is very much in accordance with pragmatic and critical views of indexing.

My main argument is that facet-analysis is based on rationalism because (1) it has not a well-developed empirical methodology (2) it ignores the theory-laden, cultural and value-based aspects of classification. In a former paper I wrote:

Facet analysis is primarily a logical approach to classification and knowledge organization. Although the methodological principles also sometimes mention empirical elements (such as examining a representative sample of texts) and pragmatic criteria (such as producing the most helpful classification), these elements are so vaguely peripherally described that they do not change the general conclusion of FA as a rationalist approach based on a priori knowledge, not on empirical knowledge or on historical or pragmatic methods (Hjørland, 2013a).

Satija (1992) is a monograph that makes a conclusion in contradiction with mine. The rest of the authors mentioned in the title of this paper have, in different ways, discussed or criticised my view. In particular, my claim that facet analysis should be considered a rationalist position has been challenged. This paper considers the arguments that these authors have provided.

\subsection{Satija (1992)}

My interpretation about the lack of empirical basis of Ranganathan's system seems to be directly opposed to the conclusion made by Satija $(1992,63)$, who wrote: "Like any true scientist, Ranganathan started not with theory but with facts. Any science is rationality rooted in facts. Verifiable facts are its basis. Facts are primarily obtained by observation," and (147) "In his academic and intellectual life, he [Ranganathan] was a staunch positivist, camping with Auguste Comte, John Lock [sic], John Stuart Mill and Ernest Mach. His power of observation was very keen."

A whole chapter is devoted to "Observations and getting the facts: Collection of data." However, almost all examples provided are about how Ranganathan educated himself, how he studied the literature about library classification, how he learned about practical issues and problems in libraries, and how he cooperated with others. None of this qualifies as empirical methodology as usually understood. A proper empirical study should instead report how given conclusions depends on reported observations (and carefully argue how the observations have been selected and which generalizations may be made from the sample observed).

The closest Satija comes to report an empirical study is the following quotation $(1992,70)$ :

His another [sic] great contribution ensues from the empirical studies. He minutely observed the way new specific subjects are formed and the knowledge is atomized in commercial houses, research and academic institutes. As a follow-up work, he advises that the entries in abstracting periodicals should be examined, grouped, tabulated and statistically studied in order to isolate the modes of formation of new specific subjects (Ranganathan 1989, sect. 3831, 271). 
This sounds as an aspiration on the part of Ranganathan to base some conclusions in bibliometric studies (by Ranganathan, 1989, 271, called "librarymetry"). However, an aspiration is not the same as completed studies. In order to qualify as empirical science, any decision about how to design a classification system should be derived from reported empirical studies. Generally this is not done in the facet-analytic tradition and the fact is that the facet-analytic tradition and the bibliometric tradition have not has much mutual influence. Satija, Madalli \& Dutta (2014, 202) wrote: "Ranganathan and McGarry mostly discovered these modes [of how new specific subjects are formed] by impliedly empirical studies based on the published literature. Ranganathan was more speculative and intuitive." This remark seems like a retreat from Satija's (1992) claim that Ranganathan's findings are empirically based.

Ranganathan's famous five categories (PMEST) are, for example, not derived from reported empirical studies. When consulting his work (such as his Prolegomena to library classification from 1967) principles are listed without any reference to empirical studies from which they should be derived. Part P (Formation, structure and development of subjects) makes no reference to the above mentioned librarymetric studies.

Vickery (1960) also describes the methodology of faceted classification schemes without describing the empirical basis of collection the scientific terms on which the systems are constructed. Finally, the Bliss Bibliographic Classification, $2^{\text {nd }}$ ed., developed in London by the Bliss Classification Association (Mills and Broughton, 1977-), which probably is the most advanced classification system developed in the facet-analytic tradition, fails to describe its empirical basis. The first volume contains a comprehensive description of the methodology on which the system is based as does each specific volume. It is obvious that the classification of a given domain is based on the collection of terminology in that domain. However, this empirical aspect of the methodology is not described or discussed. Therefore, I conclude, opposite Satija, that facet-analysis has not developed an empirical methodology.

\subsection{Tennis (2008)}

Joe Tennis wrote $(2008,108)$ under the heading "2.1.1 Pragmatic rationalism (postulationalism)":

Ranganathan, in what can be characterized as a pragmatic rationalism, claimed that all categories of subjects could be reduced to these five [Personality, Matter, Energy, Space, and Time (PMEST)].

[Ranganathan's theory] is not a strict rationalist stance, but more of a pragmatic, if not neo- pragmatic epistemic stance and method (cf. Rorty 1982, 1999). Try it, and if it works, if it is useful, don't worry about real or true. For Ranganathan utility was the final judge. His fundamental categories were used to classify in order to save time for the reader.

This interpretation differs from others', but is an attempt to align an implicit epistemic stance with the technique of writing in order to design a system.

This quotation reflecting Ranganathan's view is somewhat surprising compared with the three following:

In effect, many authors ... have stressed how the way Colon Classification depicts reality should be seen as an expression of a Hindu worldview. It seems difficult to fully understand Ranganathan's thought if it is taken out of this context. This concerns also Ranganathan's argument for a basic set of categories. There is in fact a strict resemblance between PMEST and classical Hindu categorial system which is worth investigating more thoroughly (Mazzocchi 2013b, 768).

To discover these laws [on which Ranganathan based his classification theory] in operation was to discover the very nature and order of things, an order based on principles which are eternal, unchanging, and allencompassing. There is virtually no area of Ranganathan's work and personal life in which this quest for discovering the inner or essential order behind the visible world is absent (Miksa 1998, 67).

In the end, there is a strong indication that Ranganathan's use of faceted structure of subjects could have represented his need to find more order and regularity, in the realm of subjects, than actually exist (Miksa 1998, 73).

The three quotations seem to contradict Tennis's that categories are just pragmatic choices (and this conflict is in Ranganathan's writing, not in Tennis's). I believe that the quotations by Mazzocchi and Miksa are closer to Ranganathan's philosophy than is Tennis's. However, even if we take Tennis's quotation as the point of departure, I still would not consider Ranganathan a pragmatic philosopher, because I make a sharp distinction between "pragmatism" and "practicalism" (these terms are often confused, and Bertrand Russell was especially known for his attacks on pragmatism, which he thought was little more than epistemological relativism and short-sighted practicalism). Ranganathan probably made many practicalist decisions, but I 
consider Melvil Dewey (1851-1931) to be the main practicalist influence in library and information science. His classification system (Dewey Decimal Classification or DDC) did not attempt to optimise findability in any specific collection or for any specific user group. Nor did it try to find optimal scientific or philosophical solutions to the problem today termed "information retrieval." Instead, DDC was a compromise and a standard that could be used by many different collections. His system embodies the dream of library management far more than the dream of users. Dewey's approach — and practicalism in general - may have blocked the development of library science towards becoming a scholarly field, by not connecting the field to philosophy and subject fields. Although Dewey felt that it was important for libraries to mediate high-quality books and culture, he saw it as the job of subject specialists to make the document selection. His library science was thereby reduced to purely technical issues (and such technical issues were not understood as being connected with content, but instead were based on a dualistic view of technology and content). It is also characteristic of Dewey that he took the cultural values of his time and of his class and sex for granted; they were not examined, but rather, considered as a given.

In a similar way, Ranganathan may also be considered a practicalist classificationist researcher. In order to qualify for the label "pragmatist," one should consider that different classifications serve different goals and values, and one should explicitly discuss which values and goals a given classification should serve. By not considering such issues, Ranganathan does not deserve the label "pragmatist." Richard Rorty (mentioned by Tennis) is very explicit about the democratic ideas on which his philosophy is based, whereas Ranganathan's philosophy—as far as I can tell-is based on the assumption that it is neutral in relation to epistemological, cultural and democratic values.

Tennis (2003) also asked: "What is a domain?" I answered that question in Hjørland (2013b, 178) and shall not repeat my answer here, but I will say that the way the question is asked reveals for me an underlying rationalist way of thinking.

\subsection{Herre (2013)}

Heinrich Herre (2013, 332) found that "the ontoaxiomatic method, of graduated conceptualizations, of levels of reality, and of top-level-supported methods for ontology-development" cannot be subsumed by one of the approaches presented by Hjørland:

In Hjørland (2008), the following six approaches to $\mathrm{KO}$ are described in more detail: the traditional approach, exemplified by Bliss (1935); the facet- analytical approach, founded by Ranganathan (1933); the information retrieval tradition, discussed by Warner (2002); user-oriented views; bibliometric approaches; and domain analytic methods. The approach presented in the current paper cannot be subsumed by one of these approaches, though there are close relations to some of them that will be explicated throughout the paper.

Herre is claiming that there is a way of constructing knowledge organisation systems (KOS)-here, ontologies - that is unique in relation to the approaches that I have so far identified and discussed.

Herre's claim is difficult to answer for several reasons:

- The article often refers to many other sources, which have to be considered before the issues can be properly discussed.

- The article introduces a lot of concepts and issues that describe the system constructed by the author, but not always in ways that illuminate its epistemological basis.

- The author often declares "This is work in progress" in relation to questions of importance for the present paper.

The article presents concrete work on designing ontologies. It is of high theoretical quality. However, how a concrete domain is analysed, which theoretical assumptions are made, and how a negotiation between different views of the domain is conducted are all questions that have not been answered. Concerning facet analysis, Herre has written as follows:

An interesting project is the ontological foundation of facet theory. Various authors remark that the original ideas of Ranganathan (1933, 1957, 1965, 1998) are rather vague and insufficiently established (Hjørland 2013a; Spiteri 1998; La Barre 2010). We believe that the GFO framework is sufficient expressive to allow a ontological reconstruction of facet theory. Such a reconstruction could provide a deeper understanding of notions as facet, subject, idea, isolate, etc. This is work in progress.

The article emphasises the formal approach and may therefore be considered closest to a rationalist approach (and to facet analysis). However, further studies seem to be needed.

\subsection{Mazzocchi (2013b)}

Fulvio Mazzocchi's paper is first and foremost a contribution to understanding the work of S. R. Ranganathan 
on the basis of examining the Indian philosophical tradition and the Hindu worldview that influenced it — such as the inclination to analyse existence into fundamental categories. However, it also provides some objections to views that I have expressed:

Hjørland reframes the issue [of the nature of facet] in terms of the rationalism-empiricism debate. However the analysis of Ranganathan's thought cannot be restrained within the limits of this debate because it involves conceptual elements which are extraneous to the Western tradition. Besides we risk overlooking another important question, namely the possible cognitive role of foundational items which is beyond the rationalism-empiricism debate (Mazzocchi 2013b, 773).

In my view, there are important shared assumptions in the worldview that I have described as "rationalism" and in the worldview that Mazzocchi has described as the Hindu worldview. It is not decisive whether or not a historical connection can be established between these two traditions. The decisive issue is the nature of their assumptions (in relation to classification theory). For me, the characteristics mentioned by Mazzocchi are clearly rationalist in the sense that they share the same basic assumptions, as reflected, for example, in the quotes given above by Miksa about the belief in an underlying nature and order of things, an order based on principles that are eternal, unchanging, and all-encompassing.

Mazzocchi exemplifies what he considers to be beyond the rationalism-empiricism debate:

The dynamic process of knowledge development implies the transformation of concepts, vocabularies, methods, etc. As argued by Thomas Kuhn (1962), in the history of scientific knowledge this can correspond to a "revolution," i.e. a paradigm shift in which a new theoretical view of the world is established. However this does not mean that everything is put under discussion. For example, scientific revolutions do not impair the fundamental epistemic principles of science (e.g. observation, induction and deduction). There are certain "deep" levels of assumptions which are less exposed to transformation (and are instead used to assess the sense of it) [note omitted]. This may be applied to semantic (and general cultural) planes too. (Mazzocchi 2013b, 773)

I believe that this quotation grossly underestimates the radicalism of Kuhn's theory. The core of that theory is the theory-ladenness of observation and of the meaning of scientific terms (cf. Andersen et al. 2006). Kuhn is generally considered a philosopher associated with historicism and pragmatism, and he brought an end to logical positivism (which combined empiricism and rationalism). When Mazzocchi writes, "we risk overlooking another important question, namely the possible cognitive role of foundational items which is beyond the rationalism-empiricism debate" (2013b, 773), this is for me an indication that Mazzocchi is providing a rationalist argument: it is precisely the idea of concepts and categories fixed to the human cognitive system (and thus not empirical or culturally relative) that for me, define rationalism in classification. This rationalist view by Mazzocchi is surprising in relation to other views expressed by the same author in another article from the same year:

Tacitly or not, classificatory thinking and practice depend heavily on the underlying (ontological and) epistemological foundations.

Hermeneutics and post-positivist epistemology highlighted respectively the historicity of understanding and the incommensurability of alternative scientific theories (Mazzocchi 2013a, 370).

Since a universal or neutral meta-system is not available, each contender would naturally use his own systems to carry out this analysis. However by using one system over another for such a demonstration, we have already taken for granted that it is superior, i.e., that system is correct and others are not. In other words, what must be demonstrated is presupposed (Mazzocchi 2013a, 370).

Any classification can be seen as a reflection of the basic codes of a culture, meaning that different orders can be imposed on the world as a result of different ways of looking at it (Foucault 1970). Classifications exist because boundaries are projected on things. This implies that if we are to "view" something, something else has to be excluded (Mazzocchi 2013a, 370-371).

Yes, indeed! But none of these views has been articulated in the facet-analytic tradition. I feel fully in line with the quotations from Mazzocchi (2013a), but I feel that this view is opposed to opinions expressed in Mazzocchi (2013b).

\subsection{Dousa \& Ibekwe-SanJuan (2014)}

Dousa \& Ibekwe-SanJuan (2014) consider the concept of "epistemologico-methodological eclecticism" and show that Julius Otto Kaiser's method of systematic indexing, 
as well as Brian Vickery's method of facet analysis, combine classical features of rationalism with elements of empiricism and pragmatism; they argue that such eclecticism is the norm, rather than the exception for knowledge organisation systems (KOS) in general.

First, a few words about eclecticism based on Slife and Williams (1995). Eclecticism is defined as the tendency to use more-perhaps conflicting-theories in one's work. However, eclecticism is also a theoretical choice with important implications. An advantage in the eclectic position is that it does not discard a theory on a prejudiced attitude. In principle, it should be more open to considering the strengths and weaknesses of various positions. Although taking an eclectic approach to theory may seem to imply the suspending of belief in any given theory, it should be kept in mind-as Slife and Williams (1995, 4648) write-that eclecticism is itself a theoretical position, which implies that it is desirable to suspend theoretical judgment and commitment. Such a suspension is not a logical fact, but it is actually in itself a theory about how our research should be carried out. There are disadvantages of this view of theorising. It may, for example, lead us to believe in theories that are mutually contradictory. Eclecticism is supposed to stand outside all the various theoretical positions in the field and to take all views equally seriously. However, there exists no elevated platform from which to evaluate different views. In not explicating the basis on which theories are selected, evaluated and used, eclecticism is not taking any of the theoretical positions seriously. In the same way that a core problem with both empiricism and positivism is that they believe in observations that are independent of the observer and his/her theoretical make-up, a core problem with eclecticism is that it presupposes a neutral ground from which to judge the different theories.

Any given theory is built on assumptions and has implications, while only a small part of the assumptions and implications is carefully examined and explicated. The eclectic position is open to all the theoretical mistakes that it tries to avoid. Although eclecticism at first glance may seem to provide richer explanations because it is not bound to only one theory, it should be able to argue when and why a given theoretical view is appropriate. In doing this, the eclecticist becomes increasingly committed to a certain theoretical view. In conclusion, we may consider eclecticism as a necessary view to a certain degree, especially for the applied researcher. It should, however, be seen primarily as an interim solution, as the ultimate goal in research is to establish a coherent theoretical view without internal contradictions.

Now, back to Dousa and Ibekwe-SanJuan (2014). They may be right that eclecticism is widespread in KOS, but where does this leave us? If most KOS can be shown to depend on an eclectic combination of rationalism, empiricism, historicism and pragmatism, this is of course in itself a valuable contribution to understanding the theoretical basis of $\mathrm{KO}$. One of the problems with this conclusion is, however, that the approaches are more or less conflicting and therefore cannot just supplement each other. The same system cannot, for example be a neutral system based on logical division and at the same time be a partisan system supporting given interests. It should also be considered that each position is an ideal type. Rationalism and empiricism clearly cannot exist in a pure form: you cannot classify objects without empirical knowledge of which objects exist, or without categories and concepts in which you organise your empirical observations. It is therefore no surprise that Dousa and Ibekwe-SanJuan (2014) are able to identify some empirical and pragmatic elements in rationalist systems. As I have argued in Hjørland (2013a), facet analysis has an elaborate rationalist methodology, while its empirical and pragmatic methodology is almost absent and not specified in a way that can be considered to provide design principles for KOS.

\subsection{Conclusion}

Some authors have questioned my view that the facetanalytic school of $\mathrm{KO}$ is based on rationalism. In this paper, I have considered their arguments and maintained my position. Is this just an expression of stubbornness on my part? Why is it important whether facet analysis should be considered rationalist or not? Why is it important to classify approaches to KO based on epistemological views? My answer is that these epistemological theories provide knowledge organisation as well as information science with a fruitful theoretical foundation.

Perhaps somebody will ask why it is good for $\mathrm{KO}$ to have a fruitful theoretical foundation. Can we not just have a plurality of views and knowledge organsation systems, based on new technologies, user evaluations and market forces? My answer is that new technological solutions and market-driven developments take place all the time. Our job is to provide scholarly criteria for progress, and to try to influence developments based on scholarly theory. Therefore, the theoretical foundation of $\mathrm{KO}$ is extremely important to us. I have proposed one theoretical foundation here. I'll happily discuss other suggestions.

\section{References}

Andersen, Hanne, Barker, Peter and Xiang, Chen Xiang. 2006. The cognitive structure of scientific revolutions. Cambridge: Cambridge University Press. 
Aune, Bruce. (1970) 1995. Rationalism, empiricism and pragmatism: an introduction. New York: Random House. Reprinted, New York: McGraw-Hill, 1995.

Bliss, Henry Evelyn. 1929. The organization of knowledge and the system of the sciences. With an introduction by John Dewey. New York: Henry Holt and Co.

Cooper, William S. 1969. Is inter-indexer consistency a hobgoblin? American Documentation 20: 268-78.

Dousa, Thomas M. and Ibekwe-SanJuan, Fedelia. 2014. Epistemological and methodological eclecticism in the construction of knowledge organization systems (KOSs): the case of analytico-synthetic KOSs. In Babik, Wieslaw, ed., Knowledge organization in the 21st century: between historical patterns and future prospects: Proceedings of the Thirteenth International ISKO Conference 19-22 May 2014 Kraków, Poland. Advances in knowledge organization 14. Würzburg, Germany: Ergon, pp. 152-9.

Foucault, Michel. 1970. The order of things: an archaeology of the buman sciences. New York: Random House.

Herre, Heinrich. 2013. Formal ontology and the foundation of knowledge organization. Knowledge organization 40: 332-9.

Hjørland, Birger. 1997. Information seeking and subject representation: an activity-theoretical approach to information science. Westport \& London: Greenwood Press.

Hjørland, Birger. 2008. What is knowledge organization (KO)? Knowledge organization 35: 86-101.

Hjørland, Birger. 2013a. Facet analysis: the logical approach to knowledge organization. Information processing \& management: 545-57.

Hjørland, Birger. 2013b. Theories of knowledge organization-theories of knowledge. Knowledge organization 40: 169-81.

Hjørland, Birger and Nicolaisen, Jeppe. 2010. The epistemological lifeboat. Available at http://www.iva.dk/jni/life boat $/$ content.asp?page $=$ positions

Kuhn, Thomas S. 1962. The structure of scientific revolutions. 1st ed. Chicago, IL: University of Chicago Press.

La Barre, Kathryn. 2010. Facet analysis. Annual review of information science and technology 44: 243-84.

Mazzocchi, Fulvio. 2013a. Images of thought and their relation to classification: the tree and the net. Knowledge organization 40: 366-74.

Mazzocchi, Fulvio. 2013b. Ranganathan's universe of knowledge and categorical thinking. SRELS journal of information management 50: 763-78.

Miksa, Francis L. 1998. The DDC, the universe of knowledge, and the post-modern library. Albany, NY:Forest Press.
Mills, Jack and Broughton, Vanda. 1977. Bliss bibliographic classification (2nd ed.). Introduction and auxiliary schedules. London: Butterworth.

Ranganathan, Shiyali Ramamrita. 1933. Colon classification. London: Asia Publishing House.

Ranganathan, Shiyali Ramamrita. 1957. Prolegomena to library classification. 2nd edition. New York: Asia Publishing House.

Ranganathan, Shiyali Ramamrita. 1965. The colon classification. New Brunswick, N. J.: Graduate School of Library Service, Rutgers, the State University.

Ranganathan, Shiyali Ramamrita. 1967. Prolegomena to library classification. 3rd edition. New York: Asia Publishing House.

Ranganathan, Shiyali Ramamrita. 1989. Classification and communication. Bangalore: Sandra Ranganathan Endowment. (Reprint).

Ranganathan, Shiyali Ramamrita. 1998. A descriptive account of the colon classification. Bangalore, India: Sarada

Rorty, Richard. 1982. Consequences of pragmatism. Minneapolis: University of Minnesota Press.

Rorty, Richard. 1999. Philosophy and social hope. New York: Penguin Books.

Rowley, Jennifer E. \& Farrow, John. 2000. Organizing knowledge: an introduction to managing access to information. 3rd ed. Aldershot: Gower Publishing Company.

Satija, Mohinder Partap. 1992. S. R. Ranganathan and the method of science. New Delhi: Aditya Prakashan.

Satija, Mohinder Partap, Madalli, Devika P. and Dutta, Biswanath. 2014. Modes of growth of subjects. Knowledge organization 41: 195-204.

Slife, Brent D. and Williams, Richard N. 1995. What's bebind the research? discovering hidden assumptions in the behavioral sciences. London: SAGE Publications.

Spiteri, Louise. 1998 A simplified model for facet analysis. Canadian journal of information and library science 23: 1-30.

Tennis, Joseph T. 2003. Two axes of domains for domain analysis. Knowledge organization 30: 191-5.

Tennis, Joseph T. 2008. Epistemology, theory, and methodology in knowledge organization: toward a classification, metatheory, and research framework. Knowledge organization 35: 102-12.

Vickery, Brian Campbell. 1960. Faceted classification: A guide to the construction and use of special schemes. London: ASLIB.

Warner, Julian 2002. Forms of labour in information systems. Information research 7:4. Available at http:// informationr.net/ir/7-4/paper135.html. 